\title{
Retraction Note to: Fe-PNP Pincer Complex Immobilized on Graphene Oxide as a Catalyst for Suzuki-Miyaura Coupling Reactions
}

\author{
Lolakshi Mahesh Kumar $^{1} \cdot$ Praveen Mishra ${ }^{1} \cdot$ Badekai Ramachandra Bhat ${ }^{1}$
}

Published online: 25 September 2020

c) Springer Science+Business Media, LLC, part of Springer Nature 2020

\section{Retraction to: Catalysis Letters (2019) 149:1118-1124 https://doi.org/10.1007/s10562-019-02652-7}

The Editors have retracted this article [1]. Since publication, the article [2] that served as a basis for the synthesis of the Fe-PNP pincer complex has been retracted [3] due to the findings not being reproducible. The results of this article [1] are therefore unreliable.

P.M. agrees with the retraction. B.R.B. does not agree with the retraction. L.M.K. has not responded to any correspondence from the Publisher regarding this retraction.

\section{References}

1. Kumar LM, Mishra P, Bhat BR (2019) Fe-PNP pincer complex immobilized on graphene oxide as a catalyst for Suzuki-Miyaura coupling reactions. Catal Lett 149:1118-1124. https://doi. org/10.1007/s10562-019-02652-7

2. Kumar LM, Ansari RM, Bhat BR (2018) Retracted: Catalytic activity of $\mathrm{Fe}(\mathrm{II})$ and $\mathrm{Cu}(\mathrm{II}) \mathrm{PNP}$ pincer complexes for Suzuki coupling reaction. Appl Organometal Chem 32:e4054. https://doi. org/10.1002/aoc.4054

3. Retraction statement: Catalytic activity of $\mathrm{Fe}(\mathrm{II})$ and $\mathrm{Cu}$ (II) PNP pincer complexes for Suzuki coupling reaction. Appl Organomet Chem 34:e5671. https://doi.org/10.1002/aoc.5671

Publisher's Note Springer Nature remains neutral with regard to jurisdictional claims in published maps and institutional affiliations.

The original article can be found online at https://doi.org/10.1007/ s10562-019-02652-7.

Badekai Ramachandra Bhat

ram@nitk.edu.in

1 Catalysis and Materials Laboratory, Department of Chemistry, National Institute of Technology Karnataka, Srinivasa nagar, Surathkal 575025, India 